\title{
Vestígios Da Dança Em Florianópolis: Uma relação histórica entre dança, Epistemologias do Sul e Capitalismo
}

\author{
Vestiges of Dance In Florianópolis: A historical rela- \\ tionship between dance, Epistemologies of the South \\ and Capitalism
}

RESUMO

por Charlene Simão

\begin{abstract}
0 presente artigo traz alguns apontamentos a respeito da história de Florianópolis, com ênfase no desenvolvimento de sua dança. Esta se iniciou por meio de professores estrangeiros que ensinavam balé. Discute alguns aspectos do surgimento da dança florianopolitana, os relaciona com os conceitos de linhas abissais e Epistemologias do Sul, trazidos por Boaventura de Souza Santos (2010). E, a relação entre indústria cultural e capitalismo, pesquisados por Rosana Moura (2007). Explica como outras danças ficaram apagadas por não fazerem parte dos modelos advindos da Europa como, por exemplo, a dança dos escravos africanos e as danças desenvolvidas pelos índios Carijós, primeiros habitantes da ilha. Aponta a importância de um novo olhar para a história da dança florianopolitana. E, encerra questionando a abrangência dos modelos europeus e americanos em diversas esferas da capital e, sobretudo indaga quais seriam hoje os principais referenciais utilizados por sua dança contemporânea.
\end{abstract}

Palavras-chave: Florianópolis; História; Dança; Epistemologias do Sul; Capitalismo.

\section{ABSTRACT}

This article provides some notes about the history of Florianópolis, emphasizing the development of its dance. This was initiated by foreign teachers who taught ballet. It discusses some aspects of the rise of Florianópolis' dance, relates them to the concepts of abyssal lines and Epistemologies of South, brought by Boaventura de Souza Santos (2010) and the relationship between the culture industry and capitalism researched by Rosana Moura (2007). It explains how other dances were erased for not being part of the models coming from Europe, for example, the dance of African slaves and dances performed by carijós Indians, the first inhabitants of the island of Florianópolis. It points out the importance of a new look at the history of Florianópolis' dance. And it ends questioning the extent of the European and American models in various areas of this capital city and above all inquiries what are today the main references used for its contemporary dance.

Keywords: Florianópolis; History; Dance; Epistemologies of South; Capitalism. 


\section{Vestígios Da Dança Em Florianópolis: Uma relação histórica entre dança, Epistemologias do Sul e Capitalismo}

\section{Vestígios}

Vestígio, conforme o dicionário Houaiss (2009) significa: “1. pisada ou marca deixada por homem ou animal nos caminhos por onde passa; rastro, pegada; 2. qualquer marca, sinal de alguém que passou ou de algo que sucedeu; 3. Aquilo que restou; resto, sinal." (VESTícI0, 2009). Já o conceito de trace (DERRIDA apud. SILVA FF, 2007, p.42), "traduzido comumente como vestígio, pode ser definido como aquilo que restou de alguma coisa que se destruiu, que desapareceu, mas que não pode ser traduzido plenamente em sua origem".

Inicialmente é preciso esclarecer que este estudo investigou os restos visíveis da dança em Florianópolis. Através de materiais do passado, referentes aos espetáculos e as aulas, pode-se "reconstituir" apenas parte da experiência, pois segundo Pavis (2003, p.6) na obra Análise dos espetáculos, "seja uma encenação da qual o descritor foi testemunha ou uma restituição de uma obra do passado, restitui-se na verdade apenas alguns princípios básicos e não o evento autêntico". Neste sentido, a história da dança em Florianópolis não foi resgatada, mas, de certa forma, construída sobre os vestígios deixados pelos documentos e falas dos entrevistados. Estes vestígios aliados a algumas fontes bibliográficas resultaram em um estudo sobre as primeiras mudanças na cidade que propiciaram o desenvolvimento artístico da mesma. E, a inserção da dança através do ensino de balé clássico até o surgimento das primeiras companhias de dança da cidade apontando as inovações que essas companhias trouxeram para a cena local.

\section{Vestígios De Cidade}

No século XIX, a ilha de Santa Catarina - fundada em 1675 e nomeada como Nossa Senhora do Desterro - foi elevada à categoria de cidade. Tornou-se Capital da Província de Santa Catarina em 1823. Contudo, com a resistência da cidade à implementação da República dois séculos depois - 1889 - Desterro parou de receber recursos federais e foi tomada pelas forças do Marechal Floriano Peixoto durante a Revolução Federalista. A vitória das forças do Marechal em 3 de outubro de 1894 obrigou a mudança do nome da cidade para Florianópolis, em "homenagem" ao então presidente da República, Floriano Peixoto' (FLORIANÓPOLIS, 2012).

Através desse breve histórico podemos refletir sobre a condição de colônia da capital catarinense que foi dominada através da violência. Afirmação que pode ser averiguada observando alguns fatos da história da ilha como, por exemplo, o massacre dos índios Carijós ${ }^{2}$ pelos portugueses a fim de tomar posse de suas terras e, posteriormente a alteração do nome da cidade para Florianópolis como um ato de submissão ao Marechal Floriano Peixoto, pois se não o fizesse, Desterro seria invadida.

Esse domínio, através da apropriação e da violência, é conforme Santos (2010), no ar-

$1 \quad$ Cf. FLORIANO PEIXOTO, 2013.

$2 \quad$ Nome dado aos índios que viviam em Florianópolis no período da chegada dos colonizadores. (ALVES JR, 2000). 


\title{
Vestígios Da Dança Em Florianópolis: Uma relação histórica entre dança, Epistemologias do Sul e Capitalismo
}

tigo Para além do Pensamento abissal: das linhas globais a uma ecologia de saberes, típico da relação estabelecida entre colonizadores perante os colonizados.

\begin{abstract}
[...] em geral, a apropriação envolve incorporação, cooptação e assimilação, enquanto a violência implica destruição física, material, cultural e humana. Na prática, é profunda a interligação entre apropriação e violência. No domínio do conhecimento, a apropriação vai desde o uso de habitantes locais como guias e de conhecimentos indígenas sobre biodiversidade, enquanto a violência é exercida através da proibição do uso de línguas próprias em espaços públicos, da adoção forçada de nomes cristãos, da conversão e destruição de símbolos e lugares de culto, e de todas as formas de discriminação cultural e racial. (SANTOS, 2010, p.38)
\end{abstract}

Neste momento da historia florianopolitana, já se pode perceber o quão difícil seria manter os hábitos e costumes do povo catarinense, herdados dos índios Carijós. E, dois séculos depois, manter a herança portuguesa, já que a mudança do nome da capital representou a submissão à república e a tudo o que dela chegasse à ilha.

Já na década de 1950, conforme Flores (2006) em Estética e modernidade, à guisa de introdução, a cidade passou por um momento "modernizante", de maiores transformações. Nesse período as ruas receberam pavimentação, foi construído o Campus Universitário, criada a Diretoria de Cultura e vários edifícios foram construídos. A verticalização da cidade através da construção de edifícios representou significativa mudança para a cidade, seguindo os padrões dos grandes centros urbanos - São Paulo e Rio de Janeiro - os edifícios tornaram-se verdadeiros símbolos da modernidade. Em meio aos casarios antigos de tradição açoriana surgiam cada vez mais os arranha-céus. Todas essas inovações acarretaram não apenas mudanças na estrutura física, elas também proporcionaram novos hábitos e costumes à população. 0 desejo de "ser moderno" evidenciou-se na abertura de butiques, cafés requintados, livrarias e clubes sociais como o Clube Doze de Agosto e o Clube Seis de Janeiro.

Essa relação hierárquica com os grandes centros urbanos, através da apropriação de seus hábitos e, da crença que o que existia nesses centros era melhor e, por isso, deveria ser mais valorizado do que o que existia na cidade é explicada por Santos (2010). Para o autor são como linhas abissais não geográficas, mas sociais. Este conceito enquadra as sociedades dominantes (colonizadores), independente de sua posição geográfica, como sendo o Norte, portanto utilizando as Epistemologias do Norte e as sociedades dominadas (colonizadas) como sendo o Sul, porém estas últimas não utilizam as suas Epistemologias do Sul, pois não as validam. Tudo o que vem do "Norte Social" é considerado superior ao que existe no "Sul Social" desde o período da colonização e, conforme Santos (2010), até os dias atuais. Como os colonizadores impuseram, através da apropriação e da violência suas normas, os colonizados foram obrigados a acatá-las e aos poucos foram tomando-as como corretas e, por isso, não passíveis de serem questionadas. Sem questionamentos, todo o conhecimento que vinha do Norte aos poucos começou a ser considerado como melhor e mais correto, tornando as Epistemologias do Norte uma referência para o Sul.

0 desejo de modernizar a cidade em todos os âmbitos - seguindo os modelos de São Paulo e do Rio de Janeiro e, esses por sua vez, se inspiravam nos grandes centros eu- 


\section{Vestígios Da Dança Em Florianópolis: Uma relação histórica entre dança, Epistemologias do Sul e Capitalismo}

ropeus - alcançou também as artes e a cultura, visto que, conforme Arent (1998, p.249) em Entre o passado e o futuro, tal desejo está diretamente atrelado a herança europeia "em que a cultura adquiriu um valor de esnobismo e onde se tornou questão de status ser educado o suficiente para apreciar a cultura [...]". Assim a elite florianopolitana tornava-se cada vez mais "culta" ao assimilar hábitos e costumes vindos dos grandes centros. Esse valor dado à cultura, segundo Arent (1998, p.256) também "é uma mercadoria social que podia circular e se converter em moeda em troca de toda a espécie de valores sociais e individuais".

E, para satisfazer as inúmeras solicitações de diversos representantes da elite, o governo estadual de Jorge Lacerda apoiou os artistas locais, em 1948 proporcionou a vinda do escritor Marcos Rebelo para a Exposição de Arte Contemporânea. Segundo Lehmkuhl (2006) no artigo Os modernistas da ilha: obras e exposições do grupo de artistas plásticos de Florianópolis, o artista trouxe obras e reproduções que foram compradas pela Câmara Municipal e pela Prefeitura. Essas obras fizeram parte do acervo inicial do Museu de Artes de Santa Catarina.

Também os valores modernistas foram difundidos pelo CAM (Círculo de Arte Moderna criado em 1947), que foi responsável pela edição da Revista Sul (1948-1957). Nela foram publicados artigos, peças de teatro, poemas e contos, esses também eram ilustrados por desenhos e gravuras, sempre com o intuito de divulgar a arte moderna. Ela se tornou o mais influente veículo de informação e divulgação cultural da capital. Dentre os artistas catarinenses que prestaram serviços na revista temos: José Silveira D'ávila, Moacir Fernandes, Martinho de Haro, Hugo Mund Júnior, Hiedy de Assis Corrêa, Ernesto Meyer Filho, Aníbal Nunes Pires, Salim Miguel, Aldo Nunes, Eglê Malheiros, Dimas Rosa, Rodrigo de Haro dentre outros. Alguns desses artistas formariam em 1958 o GAPF (Grupo de Artistas Plásticos de Florianópolis).

Durante as décadas de 1950 e 1960 os ímpetos modernizantes planejados se concretizaram. E partir de 1970, a capital tornou-se um pólo do turismo nacional atraindo também turistas estrangeiros. Muitas pessoas de outros estados vieram morar na cidade, a segunda ponte que liga a ilha ao continente foi construída e a Universidade Federal de Santa Catarina foi fundada.

Além da Revista Sul, a rádio Guarujá foi outro veículo de fundamental importância para a difusão da cultura na capital. Segundo Machado (2006) em Músicas, Shows e Estrelas no dial: a Rádio Guarujá e a chegada da indústria cultural em Florianópolis, até a década de 40, a capital do Estado não possuía uma emissora de rádio. Os habitantes da cidade ouviam apenas emissoras de outros centros urbanos. Em 1942 a rádio Guarujá estreou sob um sistema de alto-falantes. Ainda segundo Machado (2006), Ivo Serrão Vieira uniu-se a dois amigos e montaram uma sociedade, com dez contos de réis compraram além dos alto-falantes de rua que foram distribuídos no centro da cidade, microfones, discos, toca-discos e uma mesa de controle. Quase um ano depois, em maio de 1943 a rádio Guarujá conseguiu transformar-se em uma verdadeira radio difusora, sob o prefixo de ZYJ-7.

Através da rádio, as informações chegaram mais rápido aos moradores da capital. Isso possibilitou que a população soubesse o que estava sendo propagada na cidade referente às artes visuais, literatura, música, peças de teatro dentre outras manifestações 


\section{Vestígios Da Dança Em Florianópolis: Uma relação histórica entre dança, Epistemologias do Sul e Capitalismo}

artísticas.

Esse ímpeto de modernizar a arte na capital também está relacionado ao desenvolvimento do capitalismo e da indústria cultual do início do século XX. De acordo com Moura (2007), em Sutis violências e o espelho midiático: uma abordagem crítica da cultura contemporânea, o consumo se constitui como forma de estar no mundo, a produção capitalista ampara a indústria cultural que se estabelece como necessidade dos sujeitos. Essas necessidades são alimentadas pelos veículos de propaganda.

Ela joga sobre o sujeito não apenas a representação de um desejo - talvez pudéssemos dizer a caricatura de um desejo, pois parece não existir mediação -, mas a promessa de realizá-lo; o sujeito absorve essa promessa enquanto possibilidade pelo consumo mesmo da coisa, na tentativa de realizar-se nela. (MOURA, 2007, p.69)

E assim vivia o povo da capital do Estado, tentando aproximar-se cada vez mais dos hábitos culturais dos grandes centros, consumindo o que chegava de São Paulo e do Rio de Janeiro vindo especialmente da Europa e dos Estados Unidos. Não à toa, surgiu nessa época a "necessidade" de as filhas da elite florianopolitana aprenderem etiqueta, o que incluía aulas de balé clássico ensinadas inicialmente por professores estrangeiros.

\section{Vestígios De Dança Na Cidade}

Diferente das artes plásticas, a dança na capital começou a se desenvolver como produto artístico, de fato, somente a partir do final da década de 1970, quando a forma de encenar espetáculos se modificou. Antes as apresentações eram restritas as mostras de coreografias de alunos realizadas ao final de cada ano pelas escolas de balé surgidas na década de 1930, depois os espetáculos passaram a ser apresentados por grupos que aspiravam à profissionalização e já utilizavam de novas técnicas de dança que surgiam na cidade. Contudo, a inserção da dança na cidade, vale ressaltar, se deu através de práticas pedagógicas.

Como se pode verificar tanto em Brehsan (2006), na monografia A formação de bailarinas e bailarinos contemporâneos em Florianópolis como em Nunes (1994), no livro A dança cênica em Florianópolis, os precursores da dança clássica na cidade foram professores estrangeiros. Na ordem de chegada à capital estão Albertina Canzo (russa), Ramon Jisnisky (norueguês) e Jaques Oliver (argentino).

Os três professores possuíam formação em Ballet Clássico e, suas apresentações de final de ano nas escolas da cidade que lecionavam eram pequenas adaptações de trechos de balés de repertório3, tal fato perdurou até a década de 1970.

De acordo com Simão (2008), na monografia A cena da dança em Florianópolis - 1972 a

3 “[...] são espetáculos que contam histórias por meio da dança, no caso o balé clássico, mímica e música. Foram escritos e montados durante o século XIX e são até hoje muito encenados e admirados. [...] 0 que define se um balé é ou não de repertório é o seu caráter universal, sua época de criação e suas remontagens sucessivas." (BOUCIER apud. AQUINO 2011). 


\section{Vestígios Da Dança Em Florianópolis: Uma relação histórica entre dança, Epistemologias do Sul e Capitalismo}

2008: vestígios e reverberações, em 1977 foi aberto, por Maria Jussara Terrats, o Studio de Dança, um espaço para o ensino de dança moderna e de Jazz Dance. Terrats nasceu em São Paulo onde estudou a técnica de Martha Graham ${ }^{4}$ e fez diversos cursos de Jazz Dance. Em Florianópolis montou um grupo de dança que incorporava as duas modalidades ensinadas em sua escola e elementos da cultura Pop que vigoravam na época, como os videoclipes que veiculavam músicas de artistas como Michael Jackson.

E em 1984 o bailarino e coreógrafo baiano Toni Príncipe veio para a ilha lecionar Jazz Dance na academia Corpo e Expressão e criou o grupo Desterro Cia. de Dança. No mesmo ano Toni Príncipe deixou a direção do grupo e Sandra Meyer assumiu em seu lugar. 0 grupo levou para a cena elementos próximos a uma estética contemporânea dos anos 1980, apresentada nos grandes centros do país, como por exemplo: inserção de elementos teatrais, experimentações em cenografia, música e figurino, utilização de imagens projetadas, movimentos de balé e dança moderna e a interatividade com as artes visuais e tecnológicas da época.

Já em 1986, na academia de dança Rodança, é criado o Cena 11 Companhia de Dança, inicialmente coreografada por Anderson Conçalves. Em 1992 Alejandro Ahmed5 assumiu a direção do grupo e também passou a coreografá-lo. Em suas montagens, aos poucos o grupo foi investindo em uma pesquisa de movimentos próprios, afastando-se aos poucos da movimentação característica do Jazz Dance. Passou a investir em elementos cênicos como cenários de grande porte e desenvolveu uma pesquisa em tecnologia e ciência associadas à dança. Também o universo da cultura Pop está presente nos trabalhos, são recorrentes as influências advindas de histórias em quadrinhos, videogames, programas de computador e música eletrônica. 0 Cena 11 foi a primeira companhia de dança profissional da cidade e continua em atividade até os dias atuais obtendo reconhecimento nacional e internacional.

Com base na descrição acima, desde a inserção do Balé clássico, apontado como marco inicial da dança em Florianópolis e trazido por professores estrangeiros, até o surgimento das primeiras companhias de dança (Studio de Dança, Ballet Desterro e Cena 11) pode-se observar que, embora houvesse uma experimentação própria, as inovações que cada companhia trouxe para a dança local tiveram interlocuções com outros centros urbanos do país e de outros países.

Inicialmente devemos refletir que o entendimento de "nascimento" da dança em Florianópolis está atrelado à ideia de uma dança hegemônica que chegou até a cidade na década de 1930, ou seja, o balé clássico. Entretanto, antes mesmo da chegada dos portugueses à ilha já existiam na região as populações indígenas e após a colonização açoriana, sabe-se que foram levados à ilha escravos negros para trabalharem nos engenhos, embora tal fato, ainda hoje, seja invisivel para muitos historiadores ${ }^{6}$. E, esses povos, não dançavam? É possível supor que sim, embora durante esta pesquisa não

$4 \quad$ Cf. SIMÃO, 2008.

$5 \quad$ Alejandro Ahmed nasceu em 1971, na cidade de Montevidéu, no Uruguai. Aos quatro anos veio para Florianópolis com a família, residiram no bairro Estreito, localizado na parte continental da cidade. Aos doze anos iniciou seus estudos em dança na modalidade de Jazz Dance. Ingressou em 1986, como bailarino, no Cena 11. Em 1990 foi para São Paulo se aperfeiçoar e integrou o Grupo Raça. Em 1992 voltou para Florianópolis e assumiu a direção do Cena 11.

6 Cf. ARCEN0, 2009. 


\section{Vestígios Da Dança Em Florianópolis: Uma relação histórica entre dança, Epistemologias do Sul e Capitalismo}

tenha encontrado material escrito sobre a dança dos índios Carijós e muito pouco sobre - Cacumbi’, dança dos africanos escravos em Florianópolis.

Como afirma Santos (2010) temos na sociedade ocidental várias linhas abissais que dividem a nossa realidade. 0 que está desse lado da linha (dos colonizadores, das sociedades metropolitanas) é visível e o que está do outro lado da linha (dos colonizados, dos territórios coloniais) é invisível, portanto inexistente. Muito provavelmente, seja por isso, que a história dos índios, intitulados Carijós pelos brancos europeus, e dos muitos africanos escravos que viveram em Florianópolis, seja difícil de ser encontrada, pois estão do outro lado da linha.

Ao longo dos quase noventa anos registrados de dança na capital catarinense percebe-se que os modelos oriundos dos grandes centros urbanos foram considerados como padrões para a dança da cidade. Santos (2010, p.39) afirma que ainda hoje perdura a antiga relação entre colonizadores e colonizados e "esta realidade é tão verdadeira hoje como era no período colonial [...]. As colônias representam um modelo de exclusão radical que permanece atualmente no pensamento e práticas modernas ocidentais tal como aconteceu no ciclo colonial".

Por isso é que temos como marco inicial da dança florianopolitana o ano de 1930, quando o balé começou a ser ensinado pela professora russa Albertina Ganzo. Ganzo que endossava todos os pré-requisitos para ser a precursora da dança na cidade: ensinava balé, ou seja, uma técnica de dança de origem europeia; a própria Ganzo era europeia; e por último, vinha do grande centro urbano brasileiro, São Paulo.

Já da década de 1970 os inovadores da dança na cidade foram coreógrafos vindos do Rio de Janeiro ou de São Paulo, eles trouxeram o Jazz Dance e a dança moderna de Marta Graham, ambas norte-americanas. Os professores, coreógrafos e bailarinos da cidade viram-se praticamente obrigados a irem até esses centros e aprenderem o que se ensinava de dança por lá. Porém não eram danças oriundas de São Paulo ou do Rio de Janeiro, eram danças europeias e norte-americanas, ou seja, para a dança florianopolitana o Norte era essas capitais, entretanto para elas, o Norte era os EUA e a Europa.

Desse modo, observando esta valorização do que vem do Norte, fica mais fácil de compreender a relação de consumo trazida pelo capitalismo, apontada anteriormente. Se o capitalismo, surgido inicialmente nos grandes centros, chegava a esse "pedacinho de terra, perdido no mar" ${ }^{\prime}$, como não se submeter, ou ainda, como não desejar o que vinha de fora se este era considerado muito melhor do que o que era local? Florianópolis queria ter cafés, boutiques, pinturas, esculturas, livrarias, clubes sociais, etiqueta, balé clássico e música erudita do mesmo modo como havia em São Paulo e no Rio de Janeiro. De acordo com Moura (2007):

No desdobramento, aspectos que dizem respeito à massificação tornam-se evidentes no consumismo e acentuados por ele. Homogeneização, integração à

$7 \quad$ Cf. ALVES. et al, 1990; SILVA JJ, 2007.

8 Termo utilizado para referir-se a Florianópolis na composição musical intitulada Rancho de amor a ilha, o hino oficial da cidade de Florianópolis, de autoria de Cláudio Alvim Barbosa (Zininho). Foi escolhido em 1965 através de um concurso promovido pela Prefeitura Municipal e oficializado pelo Projeto de Lei nć 877 de 27 de Agosto de 1968. (SILVA, 2008). 


\title{
Vestígios Da Dança Em Florianópolis: Uma relação histórica entre dança, Epistemologias do Sul e Capitalismo
}

\author{
massa, estandartização, uniformização são formas apreendidas pela técnica de \\ repetição que (re)produzem a ordem das coisas nesta forma de cultura. Men- \\ sagens, comportamentos, hábitos ficam submetidos àquelas formas, seguindo \\ a mesma lógica objetivadora da racionalidade técnica [...]. (MOURA, 2007, p.70)
}

Por conta dessa massificação, a autonomia pode ser questionada visto que se refere ao que vem de fora como melhor e o consome, não por sua real superioridade, mas sim, pelo ideário que se propaga através da indústria cultural, ou seja, quando o "manezinho"9 recusa a brincar o Boi-de-mamão ${ }^{10}$ e prefere ir passear no shopping, não o está fazendo com a autonomia que acredita. Por trás de seu desejo, está incutida a incisiva propaganda que the assegura a ida ao shopping como "melhor".

A partir desses apontamentos podemos perceber o quanto cultura e consumo estão relacionadas sendo que a cultura, através da indústria cultural, tornou-se mais um produto. Conforme Moura (2007, p. 72), a indústria cultural “estabeleceu padrões facilitadores que derivam do fortalecimento da massificação como forma de converter a cultura em apêndice daquele processo produtivo". Desse modo, a propaganda funciona como um dispositivo que auxilia a massificar a cultura.

\section{Breves Considerações}

Foram apontadas nas páginas anteriores apenas breves considerações sobre a história de Florianópolis e, em particular, a história de sua dança. Portanto, para um melhor esclarecimento sobre o assunto e, para não criar novas linhas abissais, faz-se necessário estudos mais amplos sobre 0 assunto. 0 presente texto pretendeu apenas levantar hipóteses a serem estudadas, confirmadas ou refutadas futuramente.

Vale salientar a importância desse novo olhar sobre a dança Florianopolitana, que, por enquanto, teve sua história contada - até mesmo por mim - de forma unilateral e sob a hegemonia da história da dança ocidental, através dos feitos do Norte. Acredito que estudos sobre a dança produzida em Florianópolis antes da chegada da professora Albertina Ganzo, em 1930, devem ser desenvolvidos, pois muito pouco se sabe sobre a dança na cidade antes desse período. Como, por exemplo, a dança do Pau-de-fita"1 português e a dança Cacumbi criada pelos negros escravos da cidade. Em verdade, até existem estudos culturais sobre essas manifestações, mas estudos que as compreendam como partes integrantes da história da dança florianopolitana ainda precisam ser realizados.

Quanto à dança contemporânea produzida a partir da década de 70, observam-se inovações na cena florianopolitana que foram retomadas sob diferentes óticas com o passar dos anos pelas companhias de dança contemporânea da cidade ${ }^{12}$. Conforme Simão (2008), a diversidade de estilos e de movimentos, típica das companhias atuais, surgiu

9 Denominação popular dada aos nativos de Florianópolis.

10 Cf. D’ÁVILA, 2001.

11 Cf. D'ÁVILA, 2001.

12 Como por exemplo: Siedler Cia. de Dança, Ronda Grupo de Dança, O’ctus Cia. de Atos, Andras Cia. de Dança-teatro, Aplysia Cia. de Dança, Kaiowas Cia. de Dança entre outras. 


\section{Vestígios Da Dança Em Florianópolis: Uma relação histórica entre dança, Epistemologias do Sul e Capitalismo}

principalmente nas primeiras manifestações de Jazz Dance e dança moderna do Studio de Dança. A interação entre os diversos componentes da cena (como luz, cenários, figurinos e movimentos) era evidente nas obras do Ballet Desterro. Já nos anos de 1990 com o Cena 11 temos a introdução de cenas e movimentos fragmentados, elementos tecnológicos, investigações em música e espetáculos que abordam questões atuais de nossa sociedade.

Dessas três companhias de dança, a única que existe até os dias atuais é o Cena 11. 0 seu trabalho de pesquisa coreográfica é representativo na cena da dança nacional, de tal modo que insere questões que influenciam a forma de compor dança em Florianópolis. Sob alguns aspectos, o Cena 11 poderia, então, ser considerado o Norte para a dança contemporânea florianopolitana? No momento não é possível responder a esta questão, pois isso demandaria um estudo mais aprofundado do grupo Cena 11 e da influência que exerce na dança da capital catarinense. Contudo, pela qualidade, reconhecimento e anos de história que o Cena 11 tem, o grupo tornou-se um referencial para muitos grupos locais e nacionais, principalmente para os que estão iniciando suas pesquisas em dança contemporânea.

Desse modo, devemos perceber que a relação entre Norte e Sul sociais atinge esferas muito mais amplas, que ultrapassam os domínios da dança, estão na cultura, na sociedade, na política e na economia, abarcam valores capitalistas que priorizam determinados aspectos em detrimento de outros, como por exemplo, os hábitos e costumes europeus e norte-americanos em detrimento dos hábitos indígenas e africanos. 


\section{Vestígios Da Dança Em Florianópolis: Uma relação histórica entre dança, Epistemologias do Sul e Capitalismo}

\section{Referências}

> ALVES, Jucelia Maria; LIMA, Rose Mery de; ALBUQUERQUE, Cleidi. Cacumbi: um aspecto da cultura negra em Santa Catarina. Florianópolis: Ed. da UFSC, 1990.

$>$ ALVES JR, Ozias Deodato. Os últimos Carijós. Guarani Ñanduti Rogue. [S.I.]: 2000. Disponivel em: 〈http://www.staff.uni-mainz.de/lustig/guarani/floripa/〉 Acesso em: 06 set. 2013.

> ARCENO, Edevânio Francisconi; JOHANN, Karynei. A visível conveniência historiográfica: na invisibilidade da presença escrava em Santa Catarina. HISTORIANDO. [S.I.]: 2009. Disponivel em: <http://historianovicente.blog.terra.com.br/2009/07/30/a-escravidao-em-santa-catarina/> Acesso em: 06 set. 2013.

> ARENT, Hannah. Entre o passado e o futuro. São Paulo: Ed. Perspectiva, 1998.

> AQUINO, Stela Gonçalves; SCHWARTZ, Rosana Maria. A influência do ballet de repertório do século XIX no imaginário feminino. In: JORNADA DE INICIAÇÃO CIENTíFICA, 7., 2001, São Paulo. Anais eletrônicos... São Paulo: UPM-SP, 2011. Disponível em: 〈http://www. mackenzie.br/fileadmin/Pesquisa/pibic/publicacoes/2011/pdf/jor/stela_goncalves.pdf> Acesso em: 06 set. 2013.

$>$ BREHSAN, Nastaja Roussenq. A formação de bailarinas e bailarinos contemporâneos em Florianópolis. Trabalho de conclusão de curso (Licenciatura em Ed. Artística com Habilitação em Artes Cênicas - Centro de Artes). Santa Catarina: UDESC, 2007.

> D’ÁVILA, Edison; D’ÁVILA, Márcia. Festas e Tradições Populares de Itajaí. 2. ed. Itajaí: Fundação Cenésio Miranda Lins, 2001.

> FLORES, Maria Bernadete. Estética e modernidade, a guisa de introdução. In: FLORES, Maria Bernadete; LEHMKUHL, Luciene; COLLAÇO, Vera (org.). A casa do baile: estética e modernidade em Santa Catarina. Florianópolis: Fundação Boiteux, 2006.

> FLORIANO PEIXOTO. In: WIKIPÉDIA, a enciclopédia livre. Flórida: Wikimedia Foundation, 2013. Disponível em: 〈http://pt.wikipedia.org/w/index.php?title=Floriano_Peixotoctoldid=36397980 . Acesso em: 6 set. 2013.

> FLORIANÓPOLIS. Secretaria Municipal de Turismo. Sobre Florianópolis: história. Florianópolis: 2012. Disponivel em: 〈http://www.pmf.sc.gov.br/entidades/turismo/index.php?cms=historiactmenu=5>. Acesso em: 6 set. 2013.

> LEHMKUHL, Luciene. Os modernistas da ilha: obras e exposições do grupo de artistas plásticos de Florianópolis. In: FLORES, Maria Bernadete; LEHMKUHL, Luciene; COLLAÇO, Vera (org.). A casa do bail: estética e modernidade em Santa Catarina. Florianópolis: Fundação Boiteux, 2006.

> MACHADO, Aldonei. Músicas, shows e estrelas no dial: a rádio Guarujá e a chegada da indústria cultural em Florianópolis. In: FLORES, Maria Bernadete; LEHMKUHL, Luciene; COLLAÇO, Vera (org.). A casa do baile: estética e modernidade em Santa Catarina. Floria- 


\section{Vestígios Da Dança Em Florianópolis: Uma relação histórica entre dança, Epistemologias do Sul e Capitalismo}

nópolis: Fundação Boiteux, 2006.

$>$ MOURA, Rosana. Sutis violências e o espelho midiático: uma abordagem crítica da cultura contemporânea. Porto Alegre: Editora da UFRGS, 2007.

> NUNES, Sandra Meyer. A dança cênica em Florianópolis. Cadernos de Cultura. Florianópolis: Fundação Franklin Cascaes, 1994.

> PAVIS, Patrice. A análise dos espetáculos. São Paulo: Perspectiva, 2003.

> SANTOS, Boaventura de Souza. Para além do Pensamento abissal: das linhas globais a uma ecologia de saberes. In: SANTOS, Boaventura de Souza; MENESES, Maria Paula (org.). Epistemologias do Sul. São Paulo: Cortez Editora, 2010.

> SILVA, Camila Barbosa. Quem canta seus males espanta - Rancho do amor à ilha: a cidade de Florianópolis e o processo de criação de seu hino-canção (1960-1970). TrabaIho de conclusão de curso (Bacharelado em História - Centro de Ciências Humanas da Educação). Florianópolis, UDESC, 2008.

> SILVA, Francisco de Fátima. Ás voltas com a Babel: Derrida e a tradução (Catacréstica). Sínteses - Revista dos Cursos de Pós-Graduação. [S.I.]: Unicamp, v.12, 2007. p.311-318. Disponível em: 〈http://www.iel.unicamp.br/revista/index.php/sinteses/issue/view/8> Acesso em: 06 set. 2013.

> SILVA, Jaime José da. Danças, tambores e festejos: aspectos da cultura popular negra em Florianópolis no final do século XIX ao século XX. Santa Catarina em História. [S.I.]: UFSC, v.1, n.1, 2007. Disponível em: <http://seer.cfh.ufsc.br/index.php/sceh/article/viewFile/38/44> Acesso em: 06 set. 2013.

> SIMÃO, Charlene. A cena da dança contemporânea em Florianópolis - 1972 a 2008: vestígios e reverberações. Trabalho de conclusão de curso (Licenciatura em Ed. Artística com Habilitação em Artes Cênicas - Centro de Artes). Santa Catarina: UDESC, 2008.

> VESTÍGIO. In: INSTITUTO ANTÔNIO HOUAISS. Dicionário eletrônico Houaiss da língua portuguesa. [S.I.]: Ed. Objetiva, 2009. V.1.0, 1 CD-ROM.

Charlene Simão, Mestranda em Dança pela Universidade Federalo da Bahia (UFBA) e especialista em Estudos Contemporâneos em Dança pela mesma instituição. Licenciada em Educação Artística com Habilitação em Artes Cênicas pela Universidade do Estado de Santa Catarina (UDESC). Diretora da Una Cia. de Dança. Membro do Grupo de Pesquisa Corponectivos em Dança.

charlene_octus@hotmail.com 